\title{
POTENSI HUTAN TANAMAN MAHONI (Swietenia macrophylla King) DALAM PENGENDALIAN LIMPASAN DAN EROSI (Potential of Swietenia macrophylla King Forest Plantation for Run Off and Erosion Control)
}

\author{
Mashudi*, Mudji Susanto dan Liliana Baskorowati \\ Balai Besar Penelitian Bioteknologi dan Pemuliaan Tanaman Hutan, \\ Jl. Palagan Tentara Pelajar Km. 15 Purwobinangun, Pakem, Sleman, Yogyakarta.
}

*Penulis korespondensi. Tel: 0274-895954. Email: masshudy@yahoo.com

\author{
Diterima: 29 Oktober 2015
}

Disetujui: 19 April 2016

\begin{abstract}
Abstrak
Penelitian dilaksanakan pada hutan tanaman mahoni (Swietenia macrophylla King.) umur 2, 5 dan 9 tahun yang berlokasi di Resort Polisi Hutan (RPH) Getas, Bagian Kesatuan Pemangkuan Hutan (BKPH) Monggot, Kesatuan Pemangkuan Hutan (KPH) Gundih, Jawa Tengah. Penelitian ini dilakukan untuk mengetahui kondisi komunitas vegetasi tegakan mahoni pada beberapa fase umur dan potensinya dalam pengendalian limpasan dan erosi. Masing-masing umur tanaman dibangun 2 petak ukur pengamatan limpasan dan erosi dengan ukuran 22,1 m x 4 m per petak ukur. Sebagai kontrol dibangun 2 petak ukur dengan ukuran yang sama pada lahan terbuka (tanpa tanaman). Pengamatan vegetasi juga dilakukan di dalam petak ukur pengamatan erosi. Hasil penelitian menunjukkan bahwa pengendalian erosi dan limpasan permukaan tegakan mahoni lebih banyak dikendalikan oleh keberadaan seresah dan tumbuhan bawah. Tingkat erosi yang terjadi pada tegakan mahoni umur 2, 5 dan 9 tahun menurun, yaitu masing-masing menjadi 49,4, 15,3 dan 8,7 \% dibandingkan dengan control (lahan tanpa tanaman). Besar limpasan air permukaan pada tegakan mahoni umur 2, 5 dan 9 tahun yang dicerminkan oleh nilai koefisien erosi masing-masing sebesar 0,24 (4\% terhadap kontrol), 0,19 (24 \% terhadap kontrol) dan 0,14 (44\% terhadap kontrol). Kegiatan seleksi pada kegiatan pemuliaan akan menghasilkan benih unggul yang akan meningkatkan produksi kayu (biomasa) dan menurunkan laju limpasan dan erosi.
\end{abstract}

Kata kunci: hutan tanaman, mahoni, pengendalian limpasan, pengendalian erosi.

\begin{abstract}
The research was conducted on mahogany (Swietenia macrophylla King.) plantations at 2, 5 and 9 years old located in RPH Getas, BKPH Monggot, KPH Gundih, Central Java. This study was carried out to determine the condition of vegetation communities of mahogany stand on several phases of age and its potential in controlling runoff and erosion. Two observation plots including runoff and erosion were set up by the size of $22.1 \mathrm{~m} \times 4 \mathrm{~m}$ per plot. Two plots of the same size were also set up on open land (without plants) as a control. Observation of vegetation was also carried out in the plot observations of erosion. This study revealed that the erosion and the runoff surface of mahogany stand controlled by the presence of litter and undergrowth. The level of erosion of mahogany at 2, 5 and 9 years old declined respectively from 49.4, 15.3 and 8.7\% compared to the control (soil without plants). The runoff coefficient value which showing the water runoff in stands of mahogany age of 2, 5 and 9 years were: 0.24 (4\% from the control), 0.19 (24\% from the control) and 0.14 (44\% from the control). The selection activities in tree breeding will improve seed mahogany therefore, can increase the wood production (biomass) and decrease the runoff and erosion.
\end{abstract}

Keywords: forest plantation, Swietenia macrophylla, runoff control, erosion control.

\section{PENDAHULUAN}

Kebutuhan bahan baku kayu untuk kepentingan ekspor maupun domestik terus meningkat, sementara itu potensi kayu dari hutan alam cenderung menurun dari waktu ke waktu. Untuk memenuhi laju kebutuhan kayu tersebut pengembangan hutan tanaman dengan produktivitas tinggi sangat diperlukan. Dalam implementasinya, pengembangan hutan tanaman seyogyanya tidak hanya terfokus pada aspek produksi saja tetapi juga harus mempertimbangkan aspek lingkungan terutama untuk kepentingan pengendalian limpasan dan erosi. Arsyad (2006) dan Utaya (2008) menyampaikan bahwa limpasan dan erosi dapat dikendalikan oleh vegetasi melalui peningkatan laju infiltrasi air ke dalam tanah. Kemudian Pratiwi dan Narendra (2012) menyampaikan bahwa penggunaan bahan organik juga dapat dilakukan untuk menekan laju limpasan dan erosi. Dengan kata lain biomasa (seresah) yang dihasilkan sutau tegakan hutan dapat berfungsi sebagai penghambat laju limpasan dan erosi.

Mahoni (Swietenia macrophylla King.) adalah jenis eksotis (Krisnawati dkk., 2011) yang cukup potensial untuk pengembangan hutan tanaman. 
Menurut Krisnawati dkk. (2011), total hutan tanaman mahoni di Indonesia mencapai 54.000 ha dengan produktivitas yang belum optimal. Untuk meningkatkan produktivitas dan menekan laju limpasan dan erosi, kegiatan pemuliaan sangat penting dilakukan pada jenis ini. Hasil penelitian Siregar dkk. (2007) menunjukkan bahwa walaupun mahoni di Jawa termasuk jenis eksotis tetapi keragaman genetiknya tinggi sehingga kegiatan pemuliaan masih menjanjikan untuk dilaksanakan. Melalui kegiatan pemuliaan, seleksi secara bertahap dilakukan sehingga produktivitas kayu dapat ditingkatkan dan biomasa (seresah) sebagai pengendali limpasan dan erosi juga dapat ditingkatkan .

Untuk mengetahui potensi tegakan mahoni dalam mengendalikan limpasan dan erosi maka didekati dengan melalukan penelitian pada tegakan mahoni umur muda $(<10$ tahun) yang belum termuliakan. Penelitian dilakukan pada tegakan umur muda sebab kondisi hutan tanaman yang paling peka terhadap erosi pada umumnya adalah pada fase pertumbuhan awal. Hal ini sejalan dengan hasil penelitian Supangat dan Putera (2010) pada tegakan jati, dimana kapasitas infiltrasi tanah di kawasan hutan akan semakin meningkat dengan bertambahnya umur tegakan hutan sebagai akibat meningkatnya kadungan bahan organik (seresah) di bawah tegakan. Dengan penanaman mahoni dari materi yang telah termuliakan maka produktivitas biomasa dapat ditingkatkan sehingga potensi pengendalian limpasan dan erosi diharapkan juga lebih tinggi. Untuk mendekati permasalahan tersebut, maka penelitian dilaksanakan pada tanaman mahoni umur 2, 5 dan 9 tahun dengan tujuan untuk mengetahui kondisi komunitas vegetasi tegakan mahoni pada beberapa fase umur dan potensinya dalam pengendalian limpasan dan erosi.

\section{METODE PENELITIAN}

\section{Waktu dan Lokasi}

Kegiatan penelitian dilaksanakan pada bulan Oktober sampai Desember 2012. Penelitian dilaksanakan pada hutan tanaman mahoni umur 2, 5 dan 9 tahun yang berlokasi di Resort Poliasi Hutan (RPH) Getas, Bagian Kesatuan Pemangkuan Hutan (BKPH) Monggot, Kesatuan Pemangkuan Hutan
(KPH) Gundih. Secara administrasi pemerintahan, lokasi penelitian berada dalam wilayah Desa Getas, Kecamatan Geyer, Kabupaten Purwodadi. Topografi lahan bervariasi dari datar sampai terjal dengan panjang lereng relatif pendek. Jenis tanah di lokasi penelitian termasuk ordo Entisol dengan tebal lapisan atas sekitar 10-15 cm dan kedalaman regolit mencapai lebih dari $50 \mathrm{~cm}$. Bahan induk berupa batuan sedimen lanau (shale) tercampur kapur yang mudah terfragmentasi oleh panas dan hujan. Curah hujan tahunan rata-rata sebesar $2.500 \mathrm{~mm}$ dengan variasi tahunan yang cukup besar. Menurut klasifikasi Schmidt dan Ferguson, iklim termasuk dalam tipe $\mathrm{C}$ dengan 8 bulan basah dan 3 bulan kering $(\mathrm{Q}=37,5 \%)$.

\section{Rancangan Penelitian \\ Penelitian vegetasi}

Untuk mendapatkan data pertumbuhan tanaman mahoni dibuat petak ukur (PU) yang sekaligus sebagai petak ukur pengamatan erosi dan limpasan dengan ukuran 22,1 x $4 \mathrm{~m}$. Pada setiap umur tanaman dibuat 2 buah petak ukur, sehingga jumlah petak ukur vegetasi yang dibuat sebanyak 6 buah. Di dalam setiap petak ukur vegetasi dibuat petak ukur pengamatan tumbuhan bawah dengan luas $10 \mathrm{~m}^{2}$. Di dalam petak ukur pengamatan tumbuhan bawah dibuat transek-transek dengan ukuran $1 \times 1 \mathrm{~m}$.

\section{Penelitian erosi}

Untuk pengamatan erosi, di dalam masingmasing petak ukur vegetasi dibuat petak ukur erosi dengan ukuran 22,1 x 4 m. Sebagai kontrol maka dibuat 2 buah petak ukur erosi dengan ukuran yang sama pada lahan terbuka (tanpa tanaman mahoni). Dengan demikian jumlah petak ukur erosi yang dibangun sebanyak 8 buah.

Kondisi kemiringan lahan dari 8 petak ukur erosi yang telah dibangun berkisar antara $10 \%$ sampai dengan $16 \%$. Mengingat kemiringan lahan masing-masing petak ukur tidak seragam maka dilakukan koreksi dengan nilai LS (panjang dan kemiringan lahan) dalam persamaan Universal Soil Loss Equation (USLE) untuk kelerengan sebesar 9 $\%$ (Wischmeier dan Smith, 1978), seperti disajikan pada Tabel 1.

Tabel 1. Kemiringan lahan rata-rata per petak ukur dan koreksi nilai lereng (LS).

\begin{tabular}{lcccc}
\hline \multirow{2}{*}{ Perlakuan } & \multicolumn{2}{c}{ Kemiringan lahan $(\%)$} & \multicolumn{3}{c}{ LS } \\
\cline { 2 - 5 } & Petak ukur 1 & Petak ukur 2 & Petak ukur 1 & Petak ukur 2 \\
\hline Mahoni umur 2 tahun & 12,13 & 9,90 & 1,57 & 1,15 \\
Mahoni umur 5 tahun & 12,89 & 16,51 & 1,73 & 2,58 \\
Mahoni umur 9 tahun & 9,68 & 16,70 & 1,11 & 2,63 \\
Kontrol (tanpa tanaman) & 14,40 & 14,40 & 2,06 & 2,06 \\
\hline
\end{tabular}

Sumber : Data primer terolah. 


\section{Pengumpulan Data \\ Data vegetasi}

Terdapat dua kategori vegetasi yang diamati, yaitu vegetasi tanaman pokok (mahoni) dan vegetasi lainnya (tumbuhan bawah). Pada aspek vegetasi tanaman pokok parameter yang diukur meliputi tinggi total, tinggi bebas cabang, diameter batang dan penutupan tajuk. Kemudian untuk vegetasi lainnya parameter yang diukur meliputi jenis, jumlah individu tiap jenis dan luas penutupan.

\section{Data tanah}

Sampel tanah lapisan atas $(0-20 \mathrm{~cm})$ pada masing-masing petak ukur diambil, dan selanjutnya dianalisis untuk mengetahui kandungan bahan organik, tekstur, permeabilitas dan struktur tanah kemudian digunakan dalam penetapan nilai faktor erodibilitas tanah (K) dalam USLE.

\section{Data curah hujan}

Data curah hujan primer dikumpulkan dengan alat penakar hujan manual (ombrometer) yang diamati setiap pukul 07.00 pagi.

\section{Data limpasan dan erosi}

Limpasan air permukaan (run off) dan erosi (sampel suspensi) pada masing-masing petak pengamatan diukur secara harian pada pagi hari setelah hujan dengan mencatat volume air limpasan yang tertampung pada kolektor di petak pengamatan erosi. Karena setiap petak ukur pengamatan memiliki keragaman derajat kemiringan lahan (LS) dan erodibilitas tanah (K), maka untuk memperoleh kesetaraan nilai banding antar perlakuannya, nilai hasil pengukuran erosi harus dikoreksi terlebih dahulu dengan nilai faktor LS dan K persamaan USLE (Wischmeier dan Smith, 1978). Limpasan air permukaan hasil pengukuran dikonversi menjadi nilai koefisien limpasan $(\mathrm{C})$, yaitu nilai nisbah antara limpasan air permukaan dengan hujan.

\section{HASIL DAN PEMBAHASAN}

\section{Evaluasi Vegetasi}

Berdasarkan hasil pengamatan sistem tanam yang digunakan adalah tumpangsari dengan melibatkan pesanggem. Sistem tumpangsari ini dijalankan sampai tanaman pokok berumur 2 tahun. Jenis tanaman tumpangsari yang ditanam adalah kacang tanah, jagung dan singkong. Rata-rata tinggi pohon, tinggi bebas cabang, diameter batang dan penutupan tajuk tanaman mahoni umur 2, 5 dan 9 tahun secara rinci disajikan pada Tabel 2.

Pada aspek tumbuhan bawah, jumlah tumbuhan bawah yang ditemukan saat pengamatan pada tanaman mahoni umur 2, 5 dan 9 tahun sebanyak 51 jenis (Lampiran 1). Rata-rata jumlah jenis dan kerapatan tumbuhan bawah tanaman mahoni umur 2, 5 dan 9 tahun secara rinci disajikan pada Tabel 3 .

Tabel 3. menunjukkan bahwa jumlah jenis tumbuhan bawah tanaman mahoni umur 2 tahun berbeda nyata dengan tanaman mahoni umur 5 dan 9 tahun. Hal ini terjadi karena pada tanaman mahoni umur 2 tahun lahan masih digarap secara intensif untuk tumpangsari, sehingga banyak jenis tumbuhan bawah yang tersingkir dari komunitasnya. Kemudian dari aspek kerapatan, antara komunitas tumbuhan bawah tanaman mahoni umur 2, 5 dan 9 tahun berbeda nyata semuanya. Komunitas tumbuhan bawah tanaman mahoni umur 5 tahun menunjukkan tingkat kerapatan tumbuhan bawah paling tinggi, kemudian disusul tanaman mahoni umur 2 dan 9 tahun. Hal ini terjadi berkaitan dengan tingkat pengelolaan lahan dan intensitas sinar matahari yang sampai ke lantai hutan. Pada tanaman mahoni umur 5 tahun pengelolaan lahan untuk tumpangsari sudah tidak dilakukan dan penutupan tajuk tanaman pokok relatif masih rendah $( \pm$ $39,79 \%$ ) sehingga sinar matahari yang sampai ke lantai hutan cukup tinggi, akibatnya tumbuhan bawah yang hidup cukup banyak. Untuk tanaman mahoni umur 2 tahun, walaupun penutupan tajuk tanaman pokok masih sangat rendah $( \pm 8,27 \%)$ namun lahan masih digarap secara intensif dan akibatnya banyak tumbuhan bawah yang tersingkir . Pada tanaman mahoni umur 2 tahun tumbuhan bawah yang hidup sebagian besar adalah tanaman tumpangsari (pertanian). Pada tanaman mahoni umur 9 tahun, penutupan tajuk sudah cukup rapat ( \pm $85,06 \%$ ) sehingga intensitas sinar matahari yang sampai lantai hutan sedikit, akibatnya tumbuhan bawah yang hidup terbatas jenis-jenis yang toleran.

Tabel 2. Rata-rata tinggi pohon, tinggi bebas cabang, diameter batang dan penutupan tajuk tanaman mahoni umur 2, 5 dan 9 tahun.

\begin{tabular}{|c|c|c|c|c|c|}
\hline \multirow{2}{*}{ Umur tanaman } & \multicolumn{2}{|c|}{ Tinggi (m) } & \multirow{2}{*}{$\begin{array}{c}\text { Diameter batang } \\
(\mathrm{cm})\end{array}$} & \multicolumn{2}{|c|}{ Penutupan tajuk per $\left(\mathrm{m}^{2}\right)$} \\
\hline & Pohon & Bebas cabang & & Pohon & Petak ukur erosi \\
\hline 2 tahun PU 1 & 2,36 & 0,78 & 2,82 & 0,36 & 6,09 \\
\hline 2 tahun PU 2 & 2,25 & 1,04 & 2,74 & 0,36 & 8,53 \\
\hline 5 tahun PU 1 & 5,49 & 2,02 & 6,03 & 1,84 & 34,87 \\
\hline 5 tahun PU2 & 5,80 & 2,17 & 5,01 & 1,54 & 35,46 \\
\hline 9 tahun PU 1 & 10,05 & 4,20 & 11,02 & 3,06 & 73,43 \\
\hline 9 tahun PU 2 & 10,22 & 4,07 & 11,04 & 2,57 & 76,95 \\
\hline
\end{tabular}

Sumber : data primer terolah. 
Kemudian untuk aspek dominasi dan keanekaragaman jenis, hasil perhitungan indeks dominasi dan indeks keanekaragaman jenis disajikan pada Gambar 1.

Berdasarkan hasil pengamatan, jenis tumbuhan bawah yang mendominasi pada tanaman mahoni umur 2 tahun adalah jagung (Zea mays L.) dan sintru (Clitoria ternatea L.), pada tanaman mahoni umur 5 tahun yang mendominasi adalah rumput grinting (Muehlenbergia huegelii Trin.), dan pada tanaman mahoni umur 9 tahun yang mendominasi uwi (Dioscorea alata L.) dan alang-alang (Imperata cylindrica Beauv.).

\section{Erosi dan Limpasan}

Pengukuran erosi dan limpasan permukaan dilakukan selama 2 bulan, yaitu Nopember sampai Desember. Mengingat setiap petak ukur memiliki kemiringan lahan (S) dan erodibilitas tanah (K) yang berbeda maka hasil pengamatan erosi perlu dikoreksi. Koreksi lereng dilakukan dengan mengkonversi nilai faktor LS ke nilai LS`standar (Tabel 1), sedangkan koreksi erodibilitas tanah dilakukan dengan nilai koreksi terhadap nilai $\mathrm{K}$ ratarata petak ukur kontrol, dan hasilnya disajikan pada Tabel 4.

Berdasarkan hasil koreksi nilai lereng (Tabel 1) dan erodibilitas tanah (Tabel 4) maka hasil pengukuran erosi untuk masing-masing petak ukur digunakan untuk menghitung nilai erosi terkoreksi, yang hasilnya disajikan pada Tabel 5 .

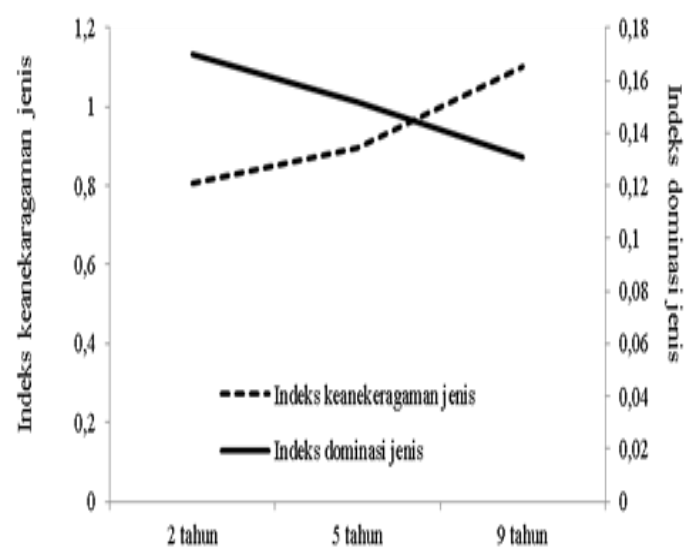

Gambar 1. Indeks dominasi jenis (C) dan indeks keanekaragaman jenis $(\mathrm{H})$ tumbuhan bawah pada tegakan mahoni umur 2, 5 dan 9 tahun.

Tabel 3. Rata-rata jumlah jenis dan kerapatan tumbuhan bawah tanaman mahoni umur 2, 5 dan 9 tahun.

\begin{tabular}{ccc}
\hline $\begin{array}{c}\text { Umur } \\
\text { (tahun) }\end{array}$ & $\begin{array}{c}\text { Jumlah jenis } \\
\text { (jenis) }\end{array}$ & $\begin{array}{c}\text { Kerapatan } \\
\text { (individu } / \mathrm{m}^{2} \text { ) }\end{array}$ \\
\hline 2 & $18 \mathrm{~b}$ & $40 \mathrm{~b}$ \\
5 & $24 \mathrm{a}$ & $92 \mathrm{a}$ \\
9 & $26 \mathrm{a}$ & $13 \mathrm{c}$ \\
\hline
\end{tabular}

Sumber : data primer terolah.

Tabel 4. Nilai erodibilitas tanah (K) hasil analisis dan setelah dikoreksi.

\begin{tabular}{lcc}
\hline \multicolumn{1}{c}{ Jenis dan umur tanaman pokok } & Hasil analisis erodibilitas tanah $(\mathrm{K})$ & Hasil koreksi nilai erodibilitas tanah (K) \\
\hline Mahoni 2 tahun PU 1 & 0,207 & 1,458 \\
Mahoni 2 tahun PU 2 & 0,116 & 0,817 \\
Mahoni 5 tahun PU 1 & 0,133 & 0,937 \\
Mahoni 5 tahun PU 2 & 0,146 & 1,028 \\
Mahoni 9 tahun PU 1 & 0,233 & 1,641 \\
Mahoni 9 tahun PU 2 & 0,224 & 1,577 \\
Kontrol PU 1 & 0,141 & 1 \\
Kontrol PU 2 & 0,143 & 1 \\
\hline
\end{tabular}

Sumber : Data primer terolah.

Tabel 5. Hasil pengukuran erosi dan nilai erosi terkoreksi pada tanaman Mahoni umur 2, 5 dan 9 tahun serta kontrol.

\begin{tabular}{|c|c|c|c|c|c|c|}
\hline \multirow{2}{*}{$\begin{array}{l}\text { Jenis dan umur } \\
\text { tanaman pokok }\end{array}$} & \multicolumn{3}{|c|}{ Nilai koreksi } & \multicolumn{2}{|c|}{ Erosi (kg/PU) } & \multirow{2}{*}{$\begin{array}{c}\text { Nilai terhadap } \\
\text { Kontrol }\end{array}$} \\
\hline & $\mathrm{LS}$ & $\mathrm{K}$ & LSxK & Pengukuran & Koreksi & \\
\hline Mahoni 2 tahun PU 1 & 1,57 & 1,46 & 2,29 & 72,40 & 31,63 & \\
\hline Mahoni 2 tahun PU 2 & 1,15 & 0,82 & 0,94 & 46,30 & 49,26 & \\
\hline Rerata & & & & 59,35 & 40,57 & 0,49 \\
\hline Mahoni 5 tahun PU 1 & 1,73 & 0,94 & 1,62 & 22,22 & 13,71 & \\
\hline Mahoni 5 tahun PU 2 & 2,58 & 1,03 & 2,62 & 30,36 & 11,45 & \\
\hline Rerata & & & & 26,29 & 12,58 & 0,15 \\
\hline Mahoni 9 tahun PU 1 & 1,11 & 1,64 & 1,82 & 17,74 & 9,74 & \\
\hline Mahoni 9 tahun PU 2 & 2,63 & 1,58 & 4,15 & 19,10 & 4,60 & \\
\hline Rerata & & & & 18,42 & 7,17 & 0,09 \\
\hline Kontrol PU 1 & 2,06 & 1 & 2,06 & 146,44 & 71,09 & \\
\hline Kontrol PU 2 & 2,06 & 1 & 2,06 & 191,82 & 93,12 & \\
\hline Rerata & & & & 169,13 & 82,11 & \\
\hline
\end{tabular}

Sumber : Data primer terolah. 
Berdasarkan hasil perhitungan (Tabel 5) tingkat erosi pada tegakan mahoni umur 2, 5 dan 9 tahun masing-masing menurun menjadi sebesar 49,4, 15,3 dan $8,7 \%$ terhadap kontrol (lahan tanpa tanaman) yang besarnya $82,11 \mathrm{~kg} /$ petak ukur $( \pm 9,3$ ton/ha). Dari angka-angka tersebut menunjukkan bahwa semakin tua umur tanaman mahoni semakin tinggi nilai erosi yang dapat dikendalikan. Hal ini sejalan dengan hasil penelitian Supangat dan Putera (2010) serta Widjajani (2010) pada jenis tanaman jati, dimana semakin tua umur tanaman tingkat erosi tanahnya semakin menurun sedangkan kemampuan intersepsinya semakin meningkat. Di samping itu Darmayanti (2012) menyampaikan bahwa letak daun mahoni yang tersebar hampir merata di seluruh cabang dengan susunan daun yang rapat menyebabkan curahan air lolos relatif kecil. Andriani dkk. (2013) juga menyampaikan bahwa semakin luas kanopi pohonnya dan semakin rapat strata daun tanamannya maka nilai air lolosnya akan semakin kecil.

Di pihak lain dengan bertambahnya umur tanaman maka rata-rata tinggi tanaman, tinggi bebas cabang dan penutupan tajuk semakin besar sehingga energi kinetik air lolos (throughfall) akan memiliki nilai yang lebih tinggi sehingga menyebabkan erosivitas menjadi tinggi. Morgan (2005) menyampaikan bahwa energi kinetik lebih sesuai untuk mengekspresikan erosivitas yang disebabkan oleh curah hujan, sedangkan Brodie dan Rosewell (2007) menyatakan bahwa energi kinetik dan momentum (kecepatan masa partikel tanah) secara praktis saling bergantian dalam perkiraan penghanyutan partikel tanah. Melihat fenomena tersebut maka pengendalian erosi pada tanaman mahoni umur 9 tahun utamanya tidak dikendalikan oleh tanaman pokok tetapi lebih dikendalikan oleh kondisi seresah dan keberadaan tumbuhan bawah.

Berdasarkan hasil pengamatan kondisi seresah di bawah tegakan mahoni umur 9 tahun cukup tebal yaitu mencapai $\pm 5 \mathrm{~cm}$ dan menutup seluruh permukaan (Gambar 2) dan kondisi tersebut didominasi (> 80\%) oleh guguran daun mahoni (Gambar 2). Hal ini sejalan dengan hasil penelitian Darmayanti dan Solikin (2013) bahwa salah satu faktor yang sangat berpengaruh terhadap limpasan permukaan dan laju infiltrasi adalah keberadaan bahan organik (seresah) yang ada di permukaan tanah.

Pada tanaman mahoni umur 5 tahun kondisi tanaman pokok relatif sudah agak besar (rata-rata tinggi berkisar 5,49-5,80 dengan penutupan tajuk $34,87-35,46 \mathrm{~m}^{2}$ per pertak ukur). Kondisi tanaman pokok tersebut sudah bisa memproduksi seresah di bawah tegakan sehingga keberadaan seresah sangat berperan dalam pengendalian erosi. Sedang pada

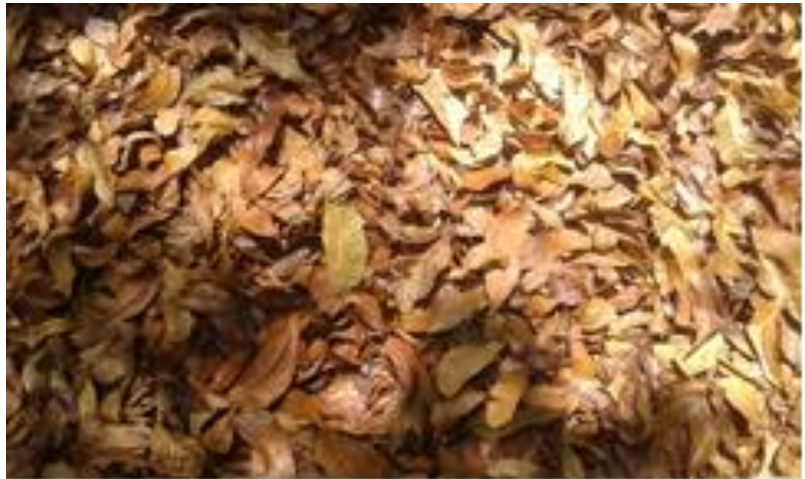

Gambar 2. Kondisi seresah di bawah tegakan mahoni umur 9 tahun.

tanaman mahoni umur 2 tahun, aktivitas tumpangsari masih dilakukan sehingga pengolahan tanah masih terjadi secara intensif, sehingga tingkat erosi masih cukup tinggi. Kemudian pada umur ini tanaman pokok masih relatif kecil (rata-rata tinggi berkisar 2,25-2,36 $\mathrm{m}$ dengan penutupan tajuk 6,09 - 8,53 $\mathrm{m}^{2}$ per pertak ukur), sehingga produksi seresah masih sangat sedikit. Menurut Tjakarwarsa dan Riyanto (2014) tingkat erosi tanah pada suatu lahan ditentukan oleh vegetasi penutup tanah dan bersarnya seresah yang ada di permukaan tanah. Pada umur 2 tahun pengendalian erosi lebih dikendalikan oleh peran tanaman lorong (lamtoro) dan mulsa sisa hasil pertanian yang sengaja ditinggalkan oleh pesanggem. Di samping itu pengendalian erosi pada umur ini banyak diperankan oleh tanaman pertanian, utamanya jagung yang ditanam cukup rapat yang mampu menutup permukaan tanah sampai $75 \%$.

Di samping itu, berdasarkan pengamatan peran tumbuhan bawah cukup penting dalam proses pengendalian erosi. Tumbuhan bawah dapat mempertahankan seresah yang ada di bawah tegakan sehingga tidak hanyut terbawa oleh aliran air waktu hujan. Berdasarkan hasil perhitungan, tumbuhan bawah pada tegakan mahoni umur 9 tahun memiliki indeks dominasi jenis $(\mathrm{C})$ yang lebih rendah $(0,131)$ dibanding tanaman mahoni umur 2 tahun $(0,170)$ dan 5 tahun $(0,152)$. Nilai indeks dominasi yang rendah berarti dominasi jenis merupakan asosiasi berbagai jenis, sedang indeks dominasi yang tinggi berarti dominasi jenis dipusatkan pada sedikit jenis. Hal ini dapat dipahami karena pada tegakan mahoni umur 2 tahun tumbuhan bawah didominasi oleh tanaman pertanian dengan jenis yang tidak banyak. Menurut Soerianegara dan Indrawan (1980) jenisjenis yang dominan mempunyai jumlah biomasa yang terbesar. Kemudian untuk keanekaragaman jenis, semakin bertambah umur tanaman mahoni semakin tinggi nilai indeks keanekaragaman tumbuhan bawahnya, dengan demikian semakin bertambah umur tanaman mahoni semakin banyak 
jenis tumbuhan bawah yang hidup. Menurut Soemarwoto (1978), nilai keanekaragaman yang tinggi akan semakin meningkatkan kestabilan lingkungan.

Berdasarkan data tersebut telah ditunjukkan bahwa peran yang sangat penting dalam pengendalian erosi hutan tanaman mahoni adalah keberadaan seresah yang secara mantap menutup lantai hutan sehingga laju erosi tanah dapat ditekan. Bertolak dari kenyataan tersebut maka kegiatan pemuliaan tanaman mahoni dalam kaitannya dengan pengendalian erosi dapat diaplikasikan. Berdasarkan hasil penelitian Siregar dkk. (2007) menunjukkan bahwa keragaman genetik tanaman mahoni relatif tinggi, sehingga dengan kegiatan pemuliaan melalui seleksi secara bertahap maka produktivitas hutan tanaman mahoni dapat ditingkatkan. Keragaman genetik sangat penting bagi kegiatan pemuliaan pohon dalam meningkatkan perolehan genetik. Secara konseptual, hubungan antara keragaman genetik dan perolehan genetik dilukiskan pada Gambar 3. Berkaitan dengan peningkatan produktivitas tersebut maka produksi biomasa daun yang nantinya akan menjadi seresah juga meningkat, sebab peningkatan tinggi tanaman, diameter batang dan luas penutupan tajuk berkorelasi positif dengan produksi biomasa daun.

Keragaman genetik yang tinggi menunjukkan bahwa variasi genetik dari individu-individu penyusun populasi cukup tinggi sehingga variasi pertumbuhan antar individu signifikan perbedaannya. Adanya variasi antar individu yang tinggi tersebut memberi peluang untuk dilakukannya seleksi, yaitu dengan tujuan untuk memilih individuindividu terbaik sebagai materi untuk membangun populasi pemuliaan. Dengan individu-individu terbaik maka benih yang dihasilkan dari populasi pemuliaan adalah bibit-bibit berkualitas. Bibit berkualitas yang dihasilkan tersebut sangat mendukung program pembangunan hutan tanaman dengan produktivitas dan tingkat pengendalian limpasan dan erosi yang tinggi .

Air hujan yang mencapai permukaan tanah akan mengalir sebagai limpasan air permukaan. Ukuran limpasan air permukaan dan koefisien limpasan pada masing-masing petak ukur pengamatan disajikan pada Tabel 6 .
Pada aspek limpasan permukaan, semakin tua tanaman mahoni maka koefisien limpasan semakin kecil (Tabel 6), yang berarti semakin tua tanaman mahoni pengendalian aliran permukaan semakin tinggi. Fenomena ini juga terjadi pada tegakan jati, dimana semakin bertambah umur tanaman limpasan permukaan semakin turun (Adinugraha dkk., 2014).

Koefisien limpasan pada tanaman mahoni umur 2 tahun $(0,24)$ sedikit di bawah dari kondisi lahan kontrol $(0,25)$. Hal ini terjadi karena pada tanaman mahoni umur 2 tahun, kegiatan tumpangsari masih berjalan sehingga lahan masih dikelola dengan intensif akibatnya aliran permukaan dari air hujan masih relatif tinggi. Pada tanaman mahoni umur 5 tahun, koefisien limpasan $(0,19)$ lebih rendah dibandingkan dengan tanaman mahoni umur 2 tahun dan kontrol. Hal ini terjadi karena pada tanaman mahoni umur 5 tahun seresah tanaman sudah mulai terakumulasi yang didukung oleh keberadaan tumbuhan bawah utamanya rumput grinting (Muehlenbergia huegelii Trin.). Koefisien limpasan pada tanaman mahoni umur 9 tahun lebih rendah dibandingkan dengan tanaman mahoni umur 2 tahun, 5 tahun serta kontrol. Hal ini terjadi karena kondisi seresah di bawah tegakan mahoni umur 9 tahun cukup tebal, yaitu mencapai $5 \mathrm{~cm}$ dan didukung oleh keberadaan tumbuhan bawah yang dapat menahan seresah sehingga tidak hanyut terbawa oleh aliran air.

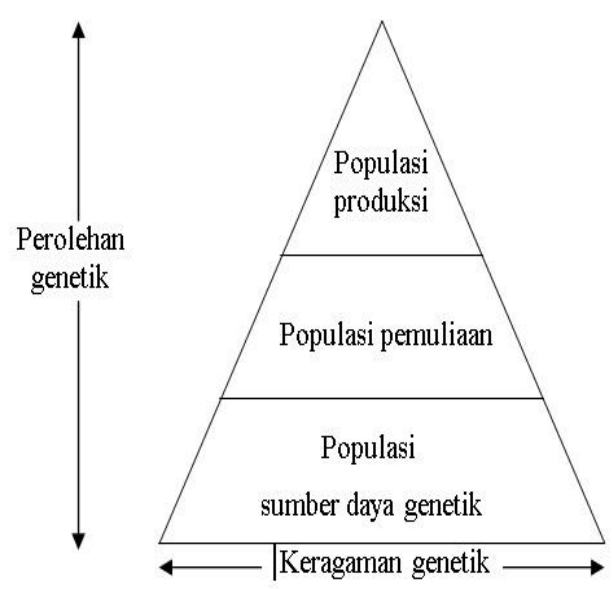

Gambar 3. Hubungan konseptual antara keragaman genetik dan perolehan genetik (Johnson dkk., 2001).

Tabel 6. Hasil pengukuran limpasan permukaan dan koefisien limpasan pada tanaman Mahoni umur 2, 5 dan 9 tahun dan kontrol.

\begin{tabular}{|c|c|c|c|c|c|}
\hline \multirow{2}{*}{$\begin{array}{l}\text { Jenis dan umur } \\
\text { tanaman pokok }\end{array}$} & \multirow{2}{*}{$\begin{array}{l}\text { Hujan } \\
(\mathrm{mm})\end{array}$} & \multicolumn{3}{|c|}{ Limpasan (mm) } & \multirow{2}{*}{$\begin{array}{l}\text { Koefisien } \\
\text { limpasan }\end{array}$} \\
\hline & & PU 1 & PU 2 & Rerata & \\
\hline Mahoni 2 tahun & 384 & 114,31 & 73,59 & 93,95 & 0,24 \\
\hline Mahoni 5 tahun & 384 & 73,82 & 75,31 & 74,57 & 0,19 \\
\hline Mahoni 9 tahun & 384 & 53,69 & 51,62 & 52,66 & 0,14 \\
\hline Kontrol & 384 & 83,08 & 106,95 & 95,02 & 0,25 \\
\hline
\end{tabular}

Sumber : Data primer terolah. 


\section{KESIMPULAN}

Pengendalian erosi dan limpasan permukaan tegakan mahoni lebih banyak dikendalikan oleh peran keberadaan seresah dan tumbuhan bawah. Kegiatan pemuliaan dengan melakukan seleksi terhadap individu-individu terbaik akan dihasilkan benih unggul mahoni yang dapat meningkatkan produksi kayu dan menurunkan limpasan permukaan dan erosi. Tingkat erosi dan besar limpasan air permukaan pada tegakan mahoni umur 2, 5 dan 9 tahun cenderung menurun dengan bertambahnya umur tanaman.

\section{DAFTAR PUSTAKA}

Adinugraha, H.A., Mashudi, dan Mahfudz. 2014. Pengaruh Asal Klon dan Jarak Tanam Terhadap Pertumbuhan Tanaman Jati dan Perannya dalam Menjaga Kualitas Lahan. Prosiding Seminar Nasional Pengelolaan DAS Terpadu untuk Kesejahteraan Masyarakat. Malang, 30 September 2014.

Andriani, S., Santosa, P.B., dan Adi, R.N., 2014. . Prosiding Seminar Nasional Pengelolaan DAS Terpadu untuk Kesejahteraan Masyarakat. Malang, 30 September 2014.

Arsyad, S. 2006. Konservasi Tanah dan Air. IPB Press, Bogor. pp: 49-54.

Brodie, I., dan Rosewell, C., 2007. Theoritical Relationship Between Rainfall Intensity and Kinetic Energy Variants Associated with Stromwater Particle Washoff. Journal of Hydrology, 340, 40-47.

Darmayanti, A.S., dan Solikin., 2013. Infiltrasi dan Limpasan Permukaan pada Pola Tanam Agroforestri dan Monokultur; Studi di Desa Jeru Kabupaten Malang. Seminar Nasional X Pendidikan Biologi FKIP UNS. Surakarta, 6 Juli 2013.

Darmayanti, A.S., 2012. Karakteristik Pohon dalam Peranannya Terhadap Infiltrasi Air Hujan di Beberapa Vak Kebun Raya Purwodadi. Tesis. Universitas Brawijaya, Malang.

Johnson R., Clair, B.S. and Lipow, S., 2001. Genetic Conservation in Applied Tree Breeding Programs. In : Thielges, B.A., Sastrapraja, S.D., and Rimbawanto, A. (Eds). Proc. Of
International Conference on In-situ and Exsitu Conservation of Commercial Tropical Trees. Yogyakarta.

Krisnawati, H., Kallio, M., dan Kanninen, M., 2011. Swietenia macrophylla King. Ecology, Silviculture and Productivity. CIFOR, Bogor. Morgan, R., 2005. Soil Erosion and Conservation. Third edition. Blackwell, Malden.

Pratiwi dan Narendra, B.H., 2012. Pengaruh Penerapan Teknik Konservasi Tanah Terhadap Pertumbuhan Pertanaman Mahoni (Swietenia macrophylla King.) di Hutan Penelitian Carita, Jawa Barat. Jurnal Penelitian Hutan dan Konservasi Alam, 9(2):139-150.

Siregar, U.J., Siregar, I.Z., dan Novita, I. 2007. Keragaman Fenotipik dan Genetik Mahoni (Swietenia macrophylla) di Jawa Tengah dan Jawa Tengah. Prosiding Seminar Nasional Hasil Penelitian yang Dibiayai oleh Hibah Kompetitif. Bogor, 1-2 Agustus 2007.

Soemarwoto., 1978. Permasalahan Lingkungan Hidup. Fakultas Kehutanan, Universitas Gadjah Mada, Yogyakarta.

Soerianegara, I., dan Indrawan, A., 1980. Ekologi Hutan Indonesia. Institut Pertanian Bogor.

Supangat, A.B., dan Putera, P.B., 2010. Kajian Infiltrasi Tanah Pada Berbagai Tegakan Jati (Tectona grandis L.) di Cepu, Jawa Tengah. Jurnal Penelitian Hutan dan Konservasi Tanah, 7(2):149-159.

Tjakarwarsa, G., dan Riyanto, H.D. 2014. Dampak Teknik Rehabilitasi Lahan Terdegradasi Terhadap Limpasan Permukaan dan Erosi. Prosiding Seminar Nasional Pengelolaan DAS Terpadu untuk Kesejahteraan Masyarakat. Malang, 30 September 2014.

Utaya, S., 2008. Pengaruh Perubahan Penggunaan Lahan Terhadap Sifat Biofisik Tanah dan Kapasitas Infiltrasi di Kota Malang. Forum Geografi, 22:99-112.

Widjajani, B.W., 2010. Tipologi Tanaman Penahan Erosi (Studi Kasus di Hutan Jati). Agrivor, 3(1):56-64.

Wischmeier, W.H., dan Smith, D.D., 1978. Predicting Rainfall Erosion Losses. A Guide to Consevation Planning Agricultural Handbook No. 537. USDA, Washington, D.C. 